\title{
Evaluate quality of urban life
}

\author{
Denis Vlasov*, Alireza Majorzadehzahiri, and Mohammad Sediq Amin \\ Moscow State University of Civil Engineering, Yaroslavskoe shosse, 26, Moscow, 129337, Russia
}

\begin{abstract}
Quality of life is one of the most important issues that has received special attention of researchers in urban planning studies today. Quality of life, while having objective dimensions and dependence on objective and mental conditions, and ultimately depends on one's perceptions and perceptions of the realities of life. Today, quality of life is the main goal of all planning produced by researchers and planners. Problems such as weak income sources, lack of public and private transportation, lack of suitable job opportunities and positions, medical centers, inadequate housing, problems and injuries caused by social inequalities, inadequate nutrition, and unsustainable housing, our urban neighborhoods Have faced challenges. The main purpose of this study is to investigate indicators related to quality of life from the perspective of citizens in Lashgar neighborhood of Tehran. The descriptive-analytical research method is based on the use of a questionnaire and in order to analyze the studied components, SPSS software and statistical methods such as mean responses, parametric t-test has been used. The results show that the quality of life in Lashgar neighborhood in environmental, economic, social, and transportation indicators in the city is not favorable from the perspective of neighborhood residents and the quality of life is low.
\end{abstract}

\section{Introduction}

Quality of life is a concept to show the level of satisfaction with life and in other words, is a criterion for determining the satisfaction and dissatisfaction of individuals and groups from different aspects of life. These dimensions can include nutrition, education, health, security, and leisure. On the other hand, in today's development planning literature, quality of life issues are considered as a continuous basic principle by development planners and managers. In discussions of quality of life, not only is life important, but its quality is important [1].

Concern about quality of life is one of the characteristics of contemporary society [2]. The field of quality of life and its measurement may never have been as wide as it is today. Economists, social scientists, and governments each look at this issue from a specific perspective [3].

Concern about quality of life is one of the characteristics of contemporary society [2]. The field of quality of life and its measurement may never have been as wide as it is today. Economists, social scientists, and governments each look at this issue from a specific perspective [3].

\footnotetext{
*Corresponding author: vlasych@mail.ru
} 
What the history of research shows is that since the beginning of the 60's, the concept of quality of life has become popular in European countries. In some advanced societies, this word was used in conjunction with and sometimes synonymously with other words such as public welfare, social welfare, social security, and the like [4].

Quality of life is a concept used to describe the development of the welfare of society. Therefore, it can be said that quality of life reflects the living conditions and well-being of individuals. Over the past 30 years, quality of life as a major goal of community development has influenced the policies of many countries [5].

The study of quality of life is the study of effective factors in feeling good, the meaning of life, and people's happiness. The theory of quality of life is to promote and develop the concepts of quality of people's living environment to provide them with the best ways of life. Therefore, the main purpose of studying the quality of life and its subsequent application is to enable people to have a high-quality life, so that this life is both purposeful and enjoyable [6].

Urban areas are very important in the planning process because they have a large population. In this regard, paying attention to the protection of quality of life rights is one of the duties of planners and those in charge of urban management. Lashgar neighborhood is one of the oldest and densest neighborhoods in Tehran, which is located in the east and seems to have many challenges in terms of quality of life (Figure 1). In this regard, this research has been done to answer the following two main questions, which are:

Are the quality of life indicators in a favorable situation from the citizens' point of view in Lashgar neighborhood?

Which component of quality of life is in good condition?

Today, there are many studies around the world on the quality of urban life [7-10], Rosen as one of the indicators of wage Quality of life surveys, meanwhile, Nord House and Tobin examined the difference in rent payments as one of the other indicators of quality of life. Improving the quality of urban life is one of the most important goals of public sector policies [11].

Depending on the type of study, each thinker defines the quality of life in his way (for example, climate pollution, housing, and poverty) and pays attention to some concepts such as health and educational achievement [12].

Table 1 shows the components of urban quality of life in the world literature based on research by scientists in various fields $[13,14]$.

Table 1. Components of quality of urban life.

\begin{tabular}{|c|c|}
\hline researchers & Components of quality of urban life \\
\hline Liu (1976) & Economy, politics, environment, community, health, and education. \\
\hline $\begin{array}{c}\text { Boyer and } \\
\text { Savageau (1981) }\end{array}$ & $\begin{array}{l}\text { Climate, housing, health and environment, crime, transportation, education, } \\
\text { art, entertainment, economics. }\end{array}$ \\
\hline $\begin{array}{l}\text { Blomquist et all } \\
(1988) \text { / Stover } \\
\text { and leven (1992) }\end{array}$ & $\begin{array}{c}\text { Precipitation, humidity, daily temperature, daily cold, wind speed, sunshine, } \\
\text { beach, heavy mass, teacher to student ratio, a field of view, airborne } \\
\text { particles, sewage discharge, property loss, credit High finance, medical } \\
\text { location, urban centers. }\end{array}$ \\
\hline Sufian (1993) & $\begin{array}{l}\text { Public safety, food cost, living space, housing standard, communications, } \\
\text { education, public health, tranquility, urban traffic, clean air. }\end{array}$ \\
\hline UNDP (1994) & Life expectancy, adult illiteracy rate, average purchasing power. \\
\hline $\begin{array}{l}\text { Protassenko } \\
\quad(1997)\end{array}$ & Monthly income per person, income distribution, monthly food expenses. \\
\hline
\end{tabular}


Quality of life, as a multidimensional and important concept in the life of today's societies, has penetrated many scientific disciplines, including urban planning and design. In issues related to urban planning, quality of life encompasses a wide range of indicators. This indicator can be classified into macro-socio-economic and environmental dimensions. Improvement of infrastructure, educational status, housing, green space, transportation are indicators of the quality of urban life, in other words, quality of life includes all aspects of human life in the city [15].

In this study, urban quality of life indicators and their components in four dimensions of transportation quality, economic quality, social quality, and environmental quality are shown in Figure 1.

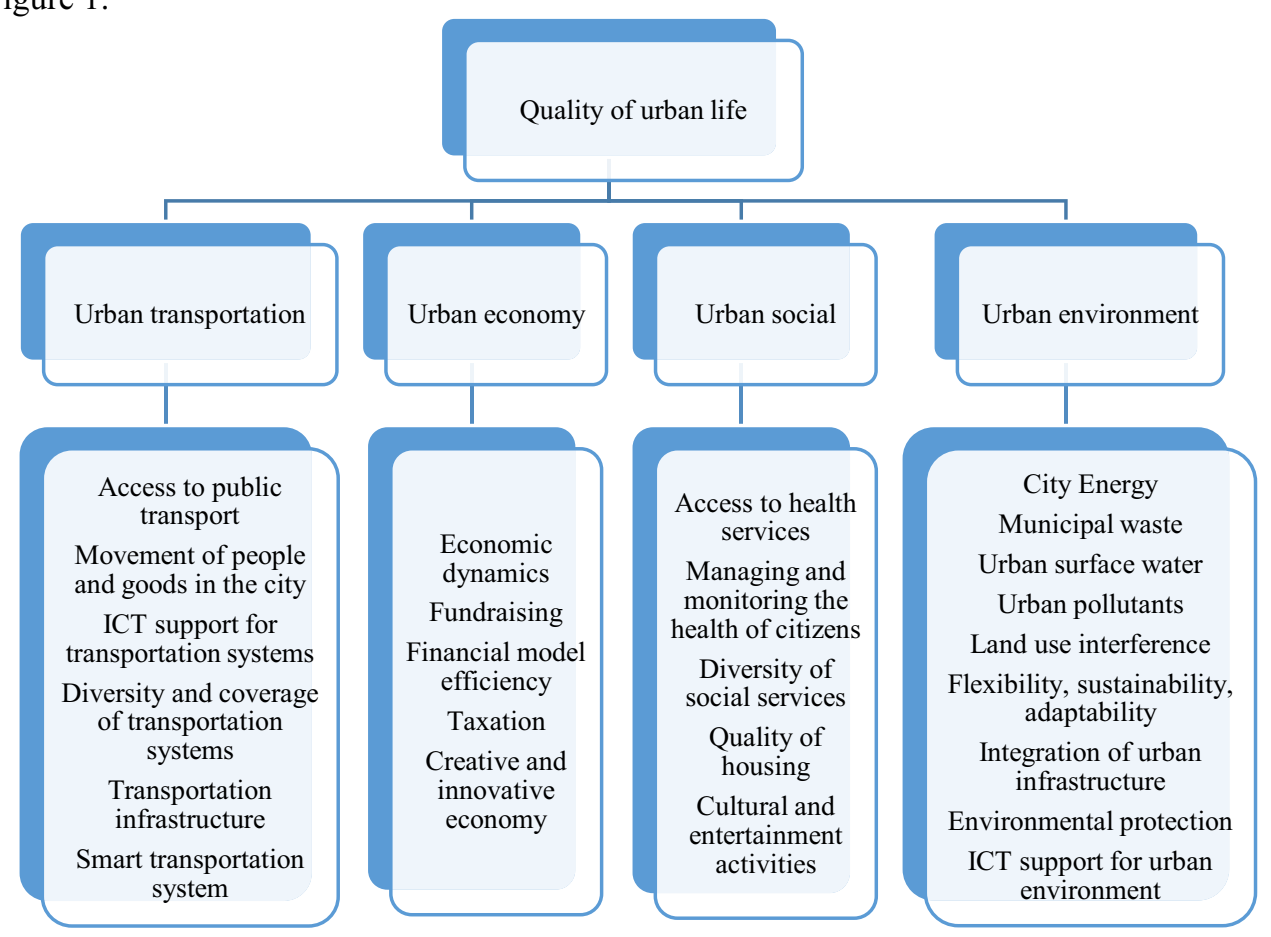

Fig. 1. Urban quality of life indicators.

\section{Methods}

This research is a descriptive-analytical method based on surveys and questionnaires. The main purpose of this study is to investigate the quality of urban life in Lashgar neighborhood in district 8 of Tehran. This neighborhood is located in the east of Tehran and is one of the oldest neighborhoods in Tehran with an area of 42 hectares (Figure 2). 


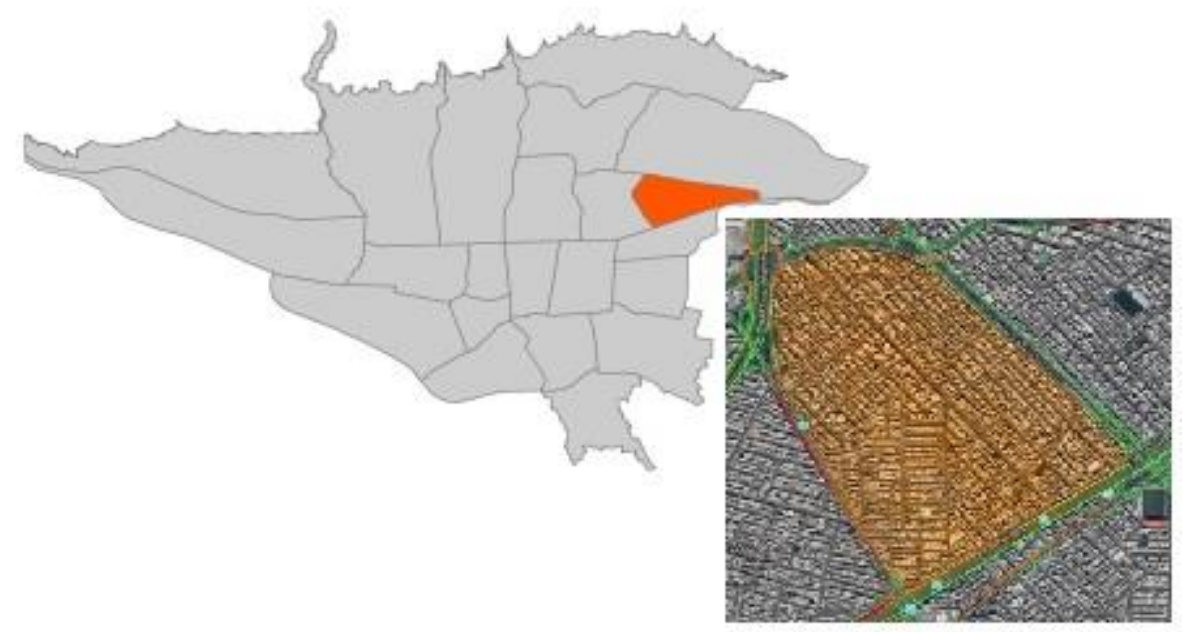

Fig. 2. Location of Lashgar neighborhood.

In order to understand the studied areas, first, the foundations of thought and other studies of researchers were studied and indicators appropriate to the study area were extracted from it and provided to the residents of this neighborhood in the form of a questionnaire.

For this purpose, based on the purpose of the research, the initial field survey in several shifts and working days and holidays, residents were questioned. To analyze and deduce, depending on the data type, scale of variables, and objectives, descriptive statistical methods such as mean, statistical analysis methods such as correlation and parametric statistical methods such as t-test have been used.

Finally, the data and answers collected from the questionnaire were analyzed by SPSS (Statistical Product and Service Solutions) software and tests in the software.

In this study, first, the status of each of the components in different dimensions of urban quality of life in Lashgar neighborhood was investigated using the data mean method. Then, t-test method was used to analyze the rejection or acceptance of the hypothesis in the sample community of Lashgar neighborhood.

In this study, the $\mathrm{H}_{0}$ (null hypothesis) indicates that the quality of urban life in Lashgar neighborhood is in a good condition from the citizens' point of view. On the other hand, $\mathrm{H}_{1}$ (alternative hypothesis) expresses the quality of urban life in Lashgar neighborhood is unfavorable from the citizens' point of view.

In fact, a one-way t-test can be used to assess the satisfaction of the studied features. Thus, if we assume that $x$ is a random variable representing the property under consideration, having satisfaction can be equated with the proposition " $\mu>a$ ", in which $\mathrm{u}$ is the mean of $\mathrm{x}$. In this test, the hypotheses are shown as follows.

$$
\begin{aligned}
& H_{0} \mu>a \\
& H_{1} \mu \leq a
\end{aligned}
$$

In this paper, for the value of $a$, which is the test value, an average score of 3 based on the Likert 5-choice spectrum is used. Therefore, in order to accept the null hypothesis in this research, two conditions are necessary: first, the p-value is greater than 0.05 and second, the $\mathrm{t}$-value is positive.

To analyze this hypothesis, in SPSS software, t-test is used, which is calculated based on equation 1 .

$$
t=\frac{\bar{x}-\mu_{0}}{s / \sqrt{n}}
$$


where $\bar{x}$ is the sample mean, $s$ is the sample standard deviation and $\mathrm{n}$ is the sample size. The degrees of freedom used in this test are $n-1$. Although the parent population does not need to be normally distributed, the distribution of the population of sample means $\bar{x}$ is assumed to be normal.

\section{Results and Discussion}

In this study, to evaluate the quality of life in Lashgar neighborhood of Tehran, different dimensions of citizens' lives were studied, the results of which are presented in each section.

\subsection{Quality of urban transportation}

Transportation as one of the main dimensions of quality of life has always been considered by experts in urban studies. The results show that the level of citizens' satisfaction in the components of access to public transport with a mean of 3.16, diversity and coverage of transportation systems with a mean of 3.13, movement of people and goods in the city with a mean of 3.03, which in these components, the mean is higher than the test value. Also in the components of transportation infrastructure with a mean of 2.61, ICT support for transportation systems with a mean of 2.59 , and smart transportation with a mean of 1.4 , which in these components, the mean is less than the test value (Table 2).

Table 2. Quality of urban transportation.

\begin{tabular}{|c|c|c|c|c|c|}
\hline \multicolumn{7}{|c|}{ One-Sample Test } \\
\cline { 2 - 6 } Transportation components & Mean & $\mathrm{t}$ & $\mathrm{df}$ & $\begin{array}{c}\text { Sig. (2- } \\
\text { tailed) }\end{array}$ & $\begin{array}{c}\text { Mean } \\
\text { Difference }\end{array}$ \\
\hline Access to public transport & 3.16 & 1.898 & 199 & 0.059 & .160 \\
\hline Movement of people and goods in the city & 3.03 & .365 & 199 & 0.716 & .025 \\
\hline ICT support for transportation systems & 2.59 & -5.626 & 199 & 0.000 & -.415 \\
\hline Diversity and coverage of transportation systems & 3.13 & 1.638 & 199 & 0.103 & .130 \\
\hline Transportation infrastructure & 2.61 & -5.839 & 199 & 0.000 & -.390 \\
\hline Smart transportation system & 2.55 & -6.362 & 199 & 0.000 & -.455 \\
\hline Urban transportation indicator & 2.84 & -3.428 & 199 & 0.001 & -.158 \\
\hline
\end{tabular}

Table 2 shows that among the transport components, only the access to public transport, diversity, and coverage of transportation systems, and movement of people and goods in the city have acceptable conditions The quality of urban life, in general, is not significant in the urban transportation indicator with a p-value of 0,001 and also the t-value is negative. Since the calculated significance level is less than 0.05 , then the null hypothesis is not acceptable and an alternative hypothesis that expresses the unsatisfactory quality of life is accepted.

\subsection{Quality of the urban economy}

The quality of the urban economy to some extent affects the dimensions of the quality of urban life. In this study, the quality indicator of the economy was examined with five components. The study of each component shows the unfavorable situation of the urban economy in the studied neighborhood according to the mean of the obtained answers. Due to the economic problems of Iran in the past few years, the low level of quality of the economy is normal. The mean of these components, which include fundraising, economic dynamics, taxation, financial model efficiency, and creative and innovative economy, are 2.78, 2.77, 
$2.73,2.14$, and 2.11 , respectively, and the mean of all components is less than the test level (Table 3).

Table 3. Quality of the urban economy.

\begin{tabular}{|c|c|c|c|c|c|}
\hline \multicolumn{7}{|c|}{ One-Sample Test } \\
\hline \multirow{2}{*}{ Economic components } & \multicolumn{5}{|c|}{ Test Value $=3$} \\
\cline { 2 - 6 } & Mean & $\mathrm{t}$ & $\mathrm{df}$ & Sig. (2 tailed) & $\begin{array}{c}\text { Mean } \\
\text { Difference }\end{array}$ \\
\hline Economic dynamics & 2.77 & -2.785 & 199 & 0.006 & -.230 \\
\hline Fundraising & 2.78 & -2.650 & 199 & 0.009 & -.220 \\
\hline Financial model efficiency & 2.14 & -11.166 & 199 & 0.000 & -.860 \\
\hline Taxation & 2.73 & -3.014 & 199 & 0.003 & -.270 \\
\hline Creative and innovative economy & 2.11 & -13.882 & 199 & 0.000 & -.890 \\
\hline Urban economy indicator & 2.51 & -10.226 & 199 & 0.000 & -.494 \\
\hline
\end{tabular}

Unfortunately, the impact of difficult economic conditions in Iran has been transferred to the city. Table 3 shows that all components of the economy and also in the urban economy indicator in general, the $\mathrm{p}$-value is not significant and the t-value is negative.

\subsection{Urban social quality}

To study the quality of social life as one of the important indicators of urban quality of life, five components have been used in this research. The results show that the component of access to health services with a mean of 3.12 is in a good condition. On the other hand, managing and monitoring the health of citizens with a mean of 2.50 is not in a good condition. Also, the component of cultural and entertainment activities with a mean of 3.16, which is higher than the test level, shows moderate quality. But other social components such as diversity of social services and quality of housing are below average with a mean of 2.64 and 2.02 (Table 4).

Table 4. Urban social quality.

\begin{tabular}{|c|c|c|c|c|c|}
\hline \multicolumn{6}{|c|}{ One-Sample Test } \\
\hline \multirow[b]{2}{*}{ Social components } & \multicolumn{5}{|c|}{ Test Value $=3$} \\
\hline & Mean & $\mathrm{t}$ & $\mathrm{df}$ & $\begin{array}{l}\text { Sig. }(2- \\
\text { tailed) }\end{array}$ & $\begin{array}{c}\text { Mean } \\
\text { Difference }\end{array}$ \\
\hline Access to health services & 3.12 & 1.603 & 199 & 0.111 & .120 \\
\hline $\begin{array}{c}\text { Managing and monitoring the health of } \\
\text { citizens }\end{array}$ & 2.50 & -7.275 & 199 & 0.000 & -.500 \\
\hline Diversity of social services & 2.64 & -4.735 & 199 & 0.000 & -.360 \\
\hline Quality of housing & 2.02 & -13.124 & 199 & 0.000 & -.980 \\
\hline Cultural and entertainment activities & 3.16 & 1.891 & 199 & 0.060 & .160 \\
\hline urban social quality indicator & 2.688 & -7.237 & 199 & 0.000 & -.31200 \\
\hline
\end{tabular}

As Table 4 shows, the overall situation of urban social quality is unfavorable because the $\mathrm{t}$-value is negative and the p-value is not significant. And in only two components of access to health services and recreational activities, Lashgar neighborhood has a relatively acceptable quality.

\subsection{Quality of urban environment}

Since quality of life does not make sense without the quality of the environment in which we live, so it can be said that the quality of the environment is an important part of quality of life 
and it includes all the components that form part of human satisfaction with the environment. Environmental quality is a complex result of the combination of mental images, values, and attitudes that vary between individuals and groups. Environmental quality can be considered as a broader understanding of quality of life. Basic quality, such as health and safety, is understood in combination with factors such as comfort and attractiveness. The mean of each of the nine key components selected to measure environmental quality is shown in Table 5, with the only component whose mean is greater than the test value being the ICT support for urban environment component with a mean of 3.08. The average of other components is less than 3 (Table 5).

Table 5. Quality of urban environment.

\begin{tabular}{|c|c|c|c|c|c|}
\hline \multicolumn{7}{|c|}{ One-Sample Test } \\
\cline { 2 - 6 } Environmental components & Mean & $\mathrm{t}$ & $\mathrm{df}$ & $\begin{array}{c}\text { Sig. (2- } \\
\text { tailed) }\end{array}$ & $\begin{array}{c}\text { Mean } \\
\text { Difference }\end{array}$ \\
\cline { 2 - 6 } & & & & .000 & -.695 \\
\hline City Energy & 2.31 & -8.527 & 199 & .000 & -.595 \\
\hline Municipal waste & 2.40 & -8.266 & 199 & .000 & -.545 \\
\hline Urban surface water & 2.46 & -7.475 & 199 & .000 & -.680 \\
\hline Urban pollutants & 2.32 & -10.069 & 199 & .000 & -.445 \\
\hline Land use interference & 2.56 & -5.762 & 199 & .000 &. .450 \\
\hline Flexibility, sustainability, adaptability & 2.55 & -5.510 & 199 & .000 & -.745 \\
\hline Integration of urban infrastructure & 2.26 & -10.160 & 199 & .000 &. .970 \\
\hline Environmental protection & 2.03 & -13.052 & 199 & .000 & .075 \\
\hline ICT support for urban environment & 3.08 & .962 & 199 & .337 & -.561 \\
\hline Urban environment quality indicator & 2.44 & -11.749 & 199 & .000 & \\
\hline
\end{tabular}

The main place of presence of people in the surrounding area is that the citizens of Lashgar neighborhood believe that the quality of the environment there is very low and the results in Table 5 show that the amount of foundation is not significant and the amount of $\mathrm{T}$ is negative. Low environmental quality in this neighborhood can be due to lack of coordination of city organs, lack of urban infrastructure, and non-implementation of urban plans. The strange result in this research is the component of ICT support for urban environment that has a medium quality. This result can be due to the use of smartphones and public applications by the majority of people and shows the growth of the smart city in Tehran, the process of which had begun in previous years in Tehran.

\section{Conclusions}

Population density in the city is one of the factors that poses major challenges to life and the environment around urban dwellers. One of these challenges is the declining quality of life of citizens. The goal of increasing the quality of life in urban areas is fair access to urban facilities and benefits. This article has been prepared with the aim of measuring the quality of life of citizens in the urban neighborhood of Lashgar Tehran. The results of this study show that in general, citizens living in Lashgar neighborhood of Tehran, because the structure of this neighborhood is declining, in terms of quality of life at a low level, on the other hand, the p-value in Indicators of quality of urban environment, the quality of urban economy, urban social quality and the quality of urban transportation are less than 0.05 and are not significant and also the t-value is negative and the null hypothesis is rejected in this study. An alternative hypothesis that reflects the low level of quality of urban life in the Lashgar neighborhood of Tehran is accepted.

Among the components related to the quality of urban life, the access to public transport with a mean of 3.16, movement of people and goods in the city with a mean of 3.3, diversity and 
coverage of transportation systems with a mean of 3.13, access to health services with a mean of 3.12, cultural and entertainment activities with a mean of 3.16 and the ICT support for urban environment with a mean of 3.08 in terms of residents of Lashgar neighborhood of Tehran have been evaluated as favorable and evaluation of other components based on the opinions of neighborhood residents shows a low level of quality of urban life.

In general, citizens are not satisfied with the selected indicators related to quality of life in Lashgar neighborhood. It should also be noted that the field study of researchers and urban data also confirms the views of citizens.

\section{References}

1. V. Cramer, S. Torgersen, E. Kringlen, Quality of Life in a City: The Effect of Population Density, Social Indicators Research, 69, 103-116 (2004)

2. M. Pacione, Urban environmental quality and human wellbeing-a social geographical perspective, Landscape and Urban Planning, 65, 19-30 (2003)

3. D. Smith, Social Justice Revisited, Environment and Planning, 32, 1149-1162 (2000)

4. R. Costanza, Quality of life: An approach integrating opportunities, human needs, and subjective well-being, Ecological Economics, 61, 56-74 (2007)

5. D. Das, Urban Quality of Life: A case study of Guwahati, Social Indicators Research, 88, 65-89 (2008)

6. M. Parker, Loss in the Lives of Southeast Asian Elders Developments in Quality of Life Studies, 1, 70 (1997)

7. S. Rosen, Wages-based indexes of urban quality of life, Urban Economics, Johns Hopkins University Press, 74-104 (1979)

8. A. M. Polinsky, D. L. Rubinfeld, Property values and the benefits of environmental improvements: theory and measurement, John Hopkins University Press, 154-180 (1977)

9. W. D. Nordhaus, J. Tobin, is growth obsolete? In Economic Research, Columbia University Press, 5, 21-49 (1972)

10. M. Getz, Y. Huang, Consumer Revealed Preference for Environmental Goods, The Review of Economics and Statistics, 60, 449-580 (1978)

11. D. Saantos, L. Martin, I. Martin, Monitoring Urban Quality of Life Experience, Social Indicators Research, 80, 411-425 (2006)

12. M. Pacione, The use of objective and subjective measures of quality of life in human geography, Prog. Hum. Geogr., 6, 495-514 (1982)

13. B. Liu, Quality of Life Indicators in U.S. Metropolitan Areas: A Statistical Analysis, Praeger, (1976)

14. B. Bullock, J. Susie, An analysis of Technology use and quality of life in a rural west texas community, university of texas, (2004)

15. B. Ulengin, U. Guvenc, A multidimensional approach to urban quality of life: The case of Istanbul, European Journal of Operational Research, 130, 361-374 (2001) 